\title{
Farnaques, jònecs i marfantes. La idiosincràsia de l'individu i del poble a través d'un recull de cultura popular
}

\author{
Carles M. Castellà Espuny \\ Universitat Rovira i Virgili \\ carlesmaria.castella@urv.cat
}

RESUM

El text presenta els resultats d'una investigació de camp en la qual s'han recollit, de manera no sistemàtica, manifestacions lingüístiques quotidianes de la cultura popular del Baix Ebre. El material inclou refranys, dites populars, fraseologia, supersticions, cançons, remeis casolans, i la seua col-lecta ha estat possible gràcies a la participació d'informants de totes les localitats del Baix Ebre. La recerca s'estructura en camps semàntics: el camp i els cultius; les indústries agrícoles; els vegetals; els animals domèstics i la vida pastoral; els animals vertebrats i invertebrats; els temps i les estacions de l'any; el cos humà; la casa; la família i el cicle de la vida; les festes populars i religioses.

En el marc del monogràfic dedicat a Identitat, folklore i educació, l'autor aprofita la presentació d'aquests materials per reflexionar sobre la necessitat que aquests continguts siguen presents a l'aula, perquè configuren la idiosincràsia de l'alumne com a persona que pertany a un poble i a un país.

La informació que hi apareix és una tria a partir de Cultura popular, folklore i etnologia del Baix Ebre (20I7), obra que va merèixer el XVII Premi Ciutat de Tortosa.

PARAULES CLAU

cultura popular; folklore; paremiologia; etnopoètica; Baix Ebre

\section{ABSTRACT}

This article presents the results of research involving the non-systematic collection of everyday language in the Baix Ebre region. The material includes proverbs, sayings, songs, superstitions, phraseology, home remedies, and so on. The author was collected the material from participants throughout the region. The material has been classified into semantic fields: agriculture and crops, agricultural industries, plants, domestic animals and rural life, vertebrate and invertebrate animals, the weather and seasons, the human body, the home, the family and life cycle, and popular and religious festivities. 
Carles M. Castellà Espuny

In the context of this monograph dedicated to identity, folklore and education, the author takes the opportunity to reflect on the need for this kind of vocabulary to be present in the classroom because as they reveal the idiosyncrasy of the student as a persona who belongs to a culture and a country.

This article is merely a selection from all of the materials that appear in the work entitled Cultura popular, folklore i etnologia del Baix Ebre (20I7), which was awarded the I7th City of Tortosa Literary Prize.

\section{KEYWORDS}

popular culture; folklore; proverbs; ethnopoetry; Baix Ebre

REBUT: 29/OI/2OI8 | ACCEPTAT: IO/O5/2OI8 


\section{Prèvia}

En el marc d'aquest número dedicat a la identitat, el folklore i l'educació, ${ }^{\mathrm{I}}$ la meua intenció és tractar les manifestacions culturals en minúscula, que s'escolen diàriament — gairebé de manera imperceptible — per boca de gent que ha viscut arraïlada a la terra i que ha sabut mantenir les expressions i la saviesa de la seua família i del seu poble.

També és necessari deixar clar que l'interès personal per la variació lingüística, d'una banda, i la realització d'enquestes i entrevistes a persones del Baix Ebre, de l'altra, es troben a la base del material recollit que, en una petita mostra, posaré a l'abast amb aquesta aportació. ${ }^{2}$ Convé tindre present que la recerca realitzada tenia un objectiu estrictament lingüístic i no cercava inicialment manifestacions relacionades amb la cultura popular ni amb el folklore, però la vitalitat de la parla d'aquests pobles i dels informants amb els quals hem conversat ha fet aflorar tot un conjunt de coneixements i d'expressions que sobreeixien de l'enquesta lingüística pròpiament dita i guarnien la recollida de dades d'una amenitat captivadora, d'una embriaguesa dolça com la de les cireres de pastor en els arboços de tardor.

La investigació es va dur a terme en un període de dos anys, entre el 2014 i el 20I6. Es va enquestar la totalitat de les poblacions del Baix Ebre (vint-i-tres), la qual cosa suposa una novetat respecte a estudis anteriors, i el nombre d'informants que hi van col-laborar va ser de vuitanta-tres (quaranta-una dones i quaranta-dos hòmens). ${ }^{3}$ Els informants havien de complir un requisit fonamental: ser oriünds de la localitat en qüestió i tindre més de seixanta anys, ja que és una generació que conserva encara un tipus de llengua genuí que no ha estat gaire influenciat per la varietat estàndard de la llengua. A part, era recomanable que posseïssen una determinada vinculació amb la terra i amb el món de la pagesia, pel fet que és aquest àmbit el que ha embolcallat la vida, les tradicions i, també, gran part de la cultura popular del segle xx a la comarca.

Els materials enregistrats s'estructuren a partir dels camps semàntics de l'enquesta $^{4}$ (el camp i els cultius, les indústries agrícoles, etc.) i no pas segons els gèneres etnopoètics.

I Aquest treball té l'origen en la intervenció duta a terme en el VII Curs de Cultura Popular celebrat a Tortosa i Jesús l'octubre de 20I7. En aquest sentit, he de donar les gràcies a l'organització per haver-me confiat aquest espai per exposar els materials de la modesta recerca que he dut a terme. Vull agrair especialment a Emili Samper i a Carme Oriol, col-legues de la URV, el fet d'haver-m'hi convidat.

2 La informació que hi apareix és una tria a partir de Castellà (20I7), obra que va merèixer el XVII Premi Ciutat de Tortosa.

3 Per cada població, el nombre d'informants fluctua entre dos i vuit, en funció de la variació que s'hi registra, de l'interès lingüístic i etnopoètic de la localitat i de la disponibilitat personal de cada individu.

4 L'enquesta està basada en els disset apartats del lèxic que presenta el qüestionari de l'Atles lingüístic del domini català (ALDC), de Joan Veny i Lídia Pons, publicats entre 200I i 20I6. A Gimeno (I997) es pot contemplar la variació lingüística existent a la comarca i en una unitat geogràfica superior, el bisbat de Tortosa, realitat que ha cohesionat històricament els pobles del centre del domini lingüístic. 


\section{Identitat, folklore i educació}

L'etnopoètica, amb tots els seus gèneres ${ }^{5}$ (la rondalla, la llegenda, la fraseologia, el relat d'experiències reals), constitueix un dels elements més representatius de la cultura d'un poble. Malauradament, moltes de les seues formes solen quedar fora del currículum educatiu o depenen, en tot cas, de la iniciativa d'algun docent que és conscient que treballar-la a classe aporta una sèrie de valors a l'estudiant. És cert que l'escola no ho pot tocar tot. Sovint se li demana implicació des de sectors molt diversos de la societat, però el marc horari és limitat. També és veritat que, quan aquests continguts sobre cultura popular apareixen en els temaris, es revesteixen d'una uniformitat que provoca que les manifestacions més particulars, les que estan lligades a l'entorn més immediat de l'alumne i de la població on viu, en queden al marge. Estandarditzar implica inevitablement arraconar les diferències i particularitats.

Amb això es vol evidenciar que els continguts que s'imparteixen a l'escola sobre aquests tipus de manifestacions solen limitar-se als símbols establerts de la comunitat autònoma amb els quals se cerca de transmetre un tipus d'identitat, l'autonòmica: valenciana (la moixiganga, el Misteri d'Elx), catalana (la sardana, el Virolai), balear (la Balenguera), aragonesa (la jota). S'acostuma a prescindir, doncs, en el nostre cas, de les manifestacions i dels símbols dels altres territoris amb qui compartim llengua, de manera que la identitat nacional queda escapçada.

També es prescindeix de les particularitats de cada poble, vila o ciutat. Coneixeu la rondalla del poble on es lliga un ruc i se l'estira fins al capdamunt del campanar perquè es menge el lletsó que hi ha crescut? On l'heu apresa? De quin poble es conta aquesta història? Hi ha espai a l'aula per a tota aquesta mena de continguts? La resposta és que sí. En primer lloc, perquè es tracta d'un tipus de coneixements que vinculen l'alumne al seu entorn més immediat i li proporcionen eines d'identificació i de socialització amb la seua localitat. Però, en segon lloc, i ja des d'un punt de vista més acadèmic i escolar, perquè des de les mateixes competències bàsiques es dona cobertura a aquests continguts (comprensió lectora, expressió escrita, comunicació oral).

El folklore, doncs, és un dels forjadors de la identitat de l'individu. Convé, per tant, que en tinguem cura ja des de l'edat escolar.

\section{La saviesa popular, la idiosincràsia d'un poble}

Hi ha un tipus de cultura que es transmet a través de llibres, obres publicades, enciclopèdies, de la qual l'escola s'ha de fer ressò i n'ha d'esdevenir altaveu. Ara bé, la primera cultura que l'individu comença a assimilar és rebuda per ell, de forma inconscient, des de la infància per via de la transmissió oral, afecta allò més proper del seu entorn i configura allò més íntim de la seua identitat: la llengua, la manera de referir-se a la realitat humana i natural que l'envolta i la manera de vincular-s'hi.

L'oralitat és el vehicle natural de la cultura popular, la qual va impregnant els diferents aspectes de la vida de la persona i en va conformant el marc de relació, des de la família fins al país, passant pel poble. I precisament aquesta oralitat, «entesa com a mitjà primigeni de comunicació i d'informació que s'esgota i es clou

5 Vegeu-ne una excel-lent descripció a Oriol (2002). 
en ell mateix després d'haver complert la seva múltiple funció social i de llenguatge, ètnica i àdhuc antropològica» (Romeu 2000: 26-27), és la que ens proporciona un seguit de manifestacions que hem volgut posar per escrit perquè, com diu l'autor citat:

L'oralitat acaba així que fineixen l'emissió de missatges i la funcionalitat en llibertat que li són propis, de manera que la transposició d'aquest cabal a l'escriptura sempre serà una necessitat que condueix inexorablement a la literatura, entesa com a mitjà necessari per al record i el testimoniatge, limitats i closos, d'una lliure activitat que ha perdut la seva essència i la seva raó última d'existir (Romeu 2000: 27).

\subsection{El camp i els cultius ${ }^{6}$}

Així, doncs, emprenem aquest trànsit de l'oralitat a l'escriptura resseguint diversos camps semàntics a partir de les manifestacions enregistrades. Per a les faenes del camp, és imprescindible conèixer les fases de la lluna, per a la qual cosa existeix una determinada fraseologia que ajuda el pagès. N'hi ha diverses, però la majoria coincideixen en l'estructura oracional i en les referències geogràfiques:

\section{Lluna vella, de cara a Morella; \\ lluna nova, de cara a la Carrova (Raval de Cristo) \\ Si la lluna mira cara a Morella, lluna vella; \\ si mira cara a Vilanova, lluna nova (Benifallet)}

Quan arriba l'hora de la collita, la faena de segar és imprescindible, però no tothom hi està capacitat o en té la possibilitat. D'aquí que l'expressió Lo qui no pot segar, espigola (Aldover), haja passat també al llenguatge comú per referir-se al consol d'algú que s'ha de conformar amb alguna cosa de menys envergadura o importància quan, en realitat, hauria preferit assolir el premi gros.

Seguint amb el camp semàntic del cereal, l'expressió Fruit tardà, ni palla ni gra (Aldover) ha traspassat també la frontera del llenguatge agrícola i al-ludeix al fet que si es deixa passar massa temps, una cosa ja no pot aprofitar per a res.

El fet que la faena al tros o a la finca no s'acomplís amb les mínimes garanties provocava l'enuig del pagès (es comprovarà com el discurs és políticament incorrecte):

Sembrat de dones, llaurat de burros i cavat de xiquets, collita de pets! (Xerta)

En algunes ocasions existeixen i circulen oralment microhistorietes referides a algun personatge - real o imaginari, però transmeses amb la certesa que va existir- relacionat amb la vida del camp o del poble. A Aldover ens expliquen la següent:

6 Reproduïm entre cometes els comentaris dels informants; en cursiva marquem els que corresponen a refranys, dites o fraseologia fixada. Entre parèntesi s'indica la localitat on s'ha enregistrat cada producció oral. 
Llaganya tenia un hort,

llaurava en un burro tort,

i la pollagana de canya.

Arri Llaganya!

En definitiva, la faena del pagès és sacrificada, constant, inajornable. I no és recomanable portar pressa ni intentar escurçar els terminis que la terra demana perquè, al final, totes les dreceres són torceres (els Reguers).

\subsection{Indústries agrícoles: vinya, olivera, blat}

\subsubsection{Vinya}

Probablement del camp semàntic de la vinya o de l'olivera procedeix aquesta expressió: «Ja hem abocat!». Ho podia dir el jornaler, al temps de la collita, quan ja tenia el cabàs ple i n'havia buidat el contingut dins la portadora, carreta o altre recipient o mitjà de transport per dur-lo al molí. La qüestió és que en pronunciar la frase ja es donava per acabada la tasca que un tenia encomanada i llavors ja no depenia d'un mateix l'èxit del procés. Avui, doncs, es diu «ja hem abocat!» quan en una situació no hi ha res a fer perquè ja s'ha produït aquell fet sobre el qual encara teníem alguna possibilitat d'intervenció (per a bé o per a mal), o perquè ha tingut lloc un esdeveniment inesperat que ens contraria (com pot ser l'aparició inesperada d'algú no desitjat en una reunió, trobada o celebració). Desconeixem l'abast geogràfic de l'exclamació.

Quan a un que va borratxo se li diu «Pareixes un bocoi!», se l'està comparant amb un recipient que té una capacitat d'uns 650 litres de vi. A les localitats que tenen o han tingut vinya no els resulta estranya l'expressió, perquè coneixen el referent, saben què és un bocoi.

\subsubsection{Olivera}

Per la importància del període hivernal de cara a la propera collita, és coneguda la dita següent:

\section{Al febrer, s'empenya l'auliver}

La dita presenta el nom de l'arbre en masculí, tot i que a la part central i meridional de la comarca la forma emprada és la femenina: aulivera.

Sobre el fruit, a part de totes les varietats existents —entre les quals les més típiques del Baix Ebre són la farga, la morruda i la sevillenca-, se'ns diu que «si minges moltes aulives, ensomiaràs» (Paüls). És una creença força estesa, no només al Baix Ebre.

7 La pollagana (pollegana en el Diccionari de la llengua catalana de l'Institut d'Estudis Catalans -DIEC) és una arada de forcat, amb braços. 


\subsubsection{Blat}

Quan era comú el fet que cada casa s'elaborés el pa, sovint es duia a terme algun tipus de prec o d'oració per tal que el procés fos reeixit: «Al preparar el llevat sempre díem "Déu que hi faigue més que jo", i encabat ho senyàvem, sas?» (Alfara de Carles). ${ }^{8}$ Després, un cop enllestit el procés, el pa, si és bo, acostuma a durar poc:

\section{Pa blan, passa volant}

Més coneguda és la metàfora que identifica la joventut amb una determinada qualitat del pa, que en aquest cas no és del tot lloable, ja que al-ludeix a la seua tendresa o manca d'experiència:

Gent jove, pa tou (la Cava)

\subsection{Vegetals}

\subsubsection{Verdures}

En la recol-lecció del panís, a l'època en la qual es duia a terme manualment i s'anava en colla, «quan te sortia una panolla roja havies de besar una xica» (Jesús i Maria). Era estrany trobar-ne una d'aquestes característiques i el fet d'aconseguir-ho comportava un premi que avui pot semblar ridícul però que per a l'interessat (i l'afectada) segur que no ho era. Amb distraccions com aquesta es devien fer més passadores les hores de treball al camp.

La majoria de comparacions estan vinculades a la característica més determinant de les verdures en qüestió. Potser en coneixeu alguna de les següents:

"A un xiquet que creix molt se li diu: "Creixes com les carabasseres"» (Benifallet).

«És més dolent que una pesteta» ${ }^{9}$ (Jesús i Maria).

«És com lo julivert, està pertot arreu» (Aldover).

\subsubsection{Plantes, arbustos, bolets}

Les dones no estaven exemptes de les faenes al camp. Al contrari, hem constatat tot sovint que són les que més coneixements tenen sobre la vida rural en general, perquè havien d'anar a ajudar al camp i, alhora, ocupar-se de totes les tasques domèstiques i de tindre cura de les criatures.

8 El caràcter sagrat del pa ve donat pel fet de ser un producte de la terra present en totes les cultures i èpoques històriques, aliment diari i, sobretot, en els països de tradició cristiana, per la seua relació amb el cos de Crist i per formar part del text de l'oració per antonomàsia, el parenostre. En algunes llars, abans de partir una barra de pa o de començar a llescar-lo, s'hi fa el senyal de la creu a la sola, amb el ganivet.

9 «Pebre coent», en el Diccionari català-valencià-balear (DCVB). Pesteta és el nom que rep majoritàriament aquesta verdura al Baix Ebre (mot no recollit pel DIEC). També registrem corolí (l'Ametlla, el Perelló) i coralet (Benifallet). El DIEC dona entrada a coralet i bitxo. 
En determinats casos, es busca simplement una revenja envers algun individu vegetal i els efectes negatius que produeix en l'ésser humà. La següent dita l'hem enregistrada a l'Aldea, Camarles i Jesús i Maria:

Ortiga de matxo, si em piques te mato.

Són conegudes les cadires de bova ${ }^{\text {IO }}$ i altres eines fabricades amb les fulles assecades d'aquesta planta. Però, a part d'això, la inflorescència que produeix, que té forma cilíndrica i és de color marronós, té una missió ben necessària i pràctica, sobretot a la ribera: «La bova, aquí dalt, fa aquells puros, que ho cremàvem para els mosquits; ficaves set o vuit puros d'estos i la fumeta aquella los fea marxar» (l'Aldea). El mateix ens diuen a l'Ampolla i a Deltebre, on aquesta part de la planta s'anomena «mascle de la bova». Sobre aquesta mateixa planta reproduïm una parèmia que va més enllà del camp semàntic del vegetal:

\section{La bova i la dona tot l'any és bona (L'Ampolla).}

Una altra planta que es collia per a altres finalitats era el junc: ${ }^{\text {II }}$ «En lo junc hi fèem les nanses ${ }^{12}$ per a agarrar les sépies» (l'Ametlla de Mar).

D'altres plantes se'n podia traure un aprofitament pecuniari: «Regalénsia! ${ }^{\mathrm{I}}$ Tanta que en vaig fer de jovenet, per estes vores de canal. Llavons les veníem als atres xiquets. Féem purets, los tallàvem i allavons a vendre regalénsia!» (Tivenys). No n'heu tastat mai?

En canvi, el roser bord o gavarrera ${ }^{\mathrm{I4}}$ fa un fruit al qual se li dona el nom de picaesquenes ${ }^{15}$ per una raó evident: «La boleta esta te ho fotien pac a atràs a l'esquena i et fotia una picassó! Ho agafaves, ho obries d'aquí dins i dins hi havien unes boletes i te ho posaven...» (Alfara de Carles).

Comparacions d'aquest apartat:

«És fina com un jasmí»" ${ }^{16}$ (l’Ametlla).

«Sempre mos va dur més rectes que un junc» (l'Ampolla).

Io Mot normatiu per a la planta del gènere Typha (també anomenada boga), les fulles de la qual es poden teixir per formar seients de cadira, cistells, etc.

II Junc és la variant emprada en el català occidental (la forma del català oriental és jonc). És un mot correcte, admès en la primera edició del DIEC (I995).

I2 «Ormeig de pesca fet de malla de jonc, vímet, canya, etc., que consisteix en una peça en forma de cúpula la base de la qual va unida a una altra peça en forma d'embut, dirigida cap a l'interior de la primera, per on entra el peix» (DIEC).

I3 Planta herbàcia de la qual s'aprofitaven les raïls com a comestibles per la seua dolçor. El nom científic, Glycyrrizha glabra, significa literalment «raïl dolça». La paraula presenta una consonant nasal típica de l’àrea de l’Ebre (la forma estàndard és regalèssia).

I4 Dos dels noms que rep al Baix Ebre aquesta planta de la família de les rosàcies, que fa flors blanques o rosades. Les dos denominacions són normatives. Respecte al fruit, allargat i rogenc, el DCVB en diu que «conté uns granets que en contacte amb la pell produeixen coïssor». Exactament el que ens van explicar a Alfara, tal com diem a dalt.

I5 Terme no recollit en el DIEC ni en el DCVB (el qual consigna grataesquenes com un dels noms del fruit, dins l'entrada gavarrera), però sí en l'excel-lent obra dirigida per Vallès (20I4).

I6 Mot no normatiu amb què es coneixen al Baix Ebre els arbustos del gènere Jasminum (DIEC: gessamí). 


\subsubsection{Fruites}

Hi ha un fruit silvestre d'aparença agradable i apetitosa que convida a ser collit i tastat: la cirera d'arboç. Aquest és el nom que recull el DIEC per al fruit de l'arbocer, tot i que al Baix Ebre pot rebre la denominació de cireres (o cireretes) de pastor en algunes poblacions. ${ }^{17}$ Doncs bé, resulta que el nom científic de l'arbust al.ludeix a una realitat que un informant de Benifallet va experimentar en primera persona.$^{18}$ Ens ho explica en aquest relat d'experiència personal: «Això són cireres de pastor. Quina borratxera me va fer agafar un dia! Això és fort, és licor! Vaig anar de petitet a parar rateres, me'n vaig fotre un fart perquè tenia gana... I em va fumar xufa perdut. No m'aclaria! Me va agarrar un mal de ventre!»

Més dolces i inofensives són les bresquilles: «Eren préssecs més petits. A vegades tiraves lo pinyol i sortien, pel secà, i se feen préssecs però més petits. Hi díem bresquilles» (Benifallet). Més d'un informant ens ha transmès la llàstima que suposa el fet que avui dia el mercat només valore la fruita pel seu aspecte i la seua mida, motiu pel qual pareix que les bresquilles estan caent en l'oblit, tot i que el mot potser seguirà viu com a metàfora per referir-se a xiquets menuts i vivaços. En aquest cas, el coneixement de mots com aquest, a part d'una identitat geogràfica, atorga als parlants que l'usen una identitat històrica, pel fet de pertànyer a una mateixa generació o per haver viscut una mateixa època, gens globalitzada.

La comparació «fas cara de maçanes agres» (Benifallet) creiem que és prou transparent i no necessita aclariment.

\subsubsection{Arbres}

Una de les finalitats de la presència de xops a les vores del riu era evitar que aquest s'anés menjant la terra de la vora. Els plantaven expressament perquè l'Ebre no la gratés. La popular expressió «Minges més que una revolta de riu!» (Tortosa) dona idea d'aquesta força erosiva del riu. Es tracta d'una dita pròpia de poblacions riberenques i probablement no serà la comparació més emprada en localitats de secà o sense aquest element geogràfic. No cal dir, doncs, que el riu marca fortament la identitat d'unes comarques com aquestes on ens trobem, terres que porten el nom del riu directament associat a la seua denominació i a la vida diària..$^{19}$

I7 Nosaltres l'hem enregistrat a l'Aldea, Aldover, Alfara, l'Ametlla, Benifallet, Bítem, Campredó, Jesús, Paüls, Tivenys, Vinallop i Xerta. Una altra manera de referir-s'hi a la comarca és alborços i variants (arborços, asborços).

I8 Arbutus unedo: arbust del qual cal menjar-ne només un (de fruit). El Grup de Recerca Científica Terres de l'Ebre (2008: I3I) explica, a més, com obtenir un licor ben gustós a partir d'aquest fruit. La seua obra (Plantes del Port, en tres volums) aporta una gran quantitat de valuosa informació sobre totes les plantes estudiades: propietats medicinals, aprofitament i utilitat de les seues parts, informació lingüística i de cultura popular.

I9 Hem inclòs aquesta dita en aquest apartat per l'explicació que diversos informants ens han proporcionat sobre el motiu de la presència de xops a la vora de l'Ebre. Potser el riu mereixeria un apartat propi, independent, però ens hem cenyit als camps semàntics predeterminats per l'enquesta que hem seguit (vegeu nota al peu 4). 
El castanyer bord va bé per al mal de queixal, segons diuen. Però no és l'única propietat curativa d'aquest fruit: «Quan tens morenes, te fiques una castanya borda a la butxaca i no se t'envinagren $»^{20}$ (Benifallet).

Com es veu, doncs, els vegetals bords tenen també utilitat i propietats. En aquesta mateixa direcció, i ara respecte a la fusta, recollim a Jesús la següent expressió rimada:

\section{Si vols fer contenta una muller, dona-li llenya de garrofer; si la vols contenta del tot, dona-li de garrofer bord. ${ }^{2 \mathrm{I}}$}

«Les anous van bé pels ossos», ens diu un informant de Benifallet. Són conegudes de molta gent les virtuts d'aquest tipus de fruits, força abundants a la nostra comarca. Pel que fa a les ametles, cal que estiguen en bones condicions perquè el mateix informant ens adverteix que «les ametles amargantes, si te'n fotesses deu u dotze, te podrien matar». El que és cert és que la fascinació i el respecte que produeix el món de la mort es troba a l'origen de moltes de les creences i és un element imprescindible per entendre part de les pràctiques, les tradicions i les supersticions d'una localitat o d'una cultura.

Pel que fa a les comparacions d'aquesta secció, n'esmentem les següents:

«A un xiquet que creix molt se li diu: "Pareixes un pi d'aubaga"» (Benifallet).

«Ets una fulla de pi» (Benifallet), en el sentit de no valer res.

«És més estreta que una fulla de pi» (Alfara de Carles).

\subsection{Animals domèstics i vida pastoral}

Porc a miges, ${ }^{22}$ sempre gruny, ens diuen a Camarles, i es pot deduir que la parèmia no es refereix especialment a l'estat de l'animal, sinó, per exemple, al fet de deixar a mitges alguna labor $i$ als efectes negatius que produeix aquesta faena inacabada en la persona que l'experimenta. Però si ens centrem en la seua literalitat, la dita té una altra explicació: el porc que es té a mitges, és a dir, en copropietat, sovint passa gana, perquè els dos propietaris esperen que siga l'altre qui l'alimente. Així, tal com recull el DCVB en una dita semblant, «els negocis que es porten a mitges no solen donar prou beneficis a cap dels dos participants». ${ }^{23}$

Per un altre costat, l'experiència ens diu que els excessos no són bons i tindre totes les necessitats cobertes no comporta obligatòriament una satisfacció i una

20 El verb envinagrar presenta aquí el sentit figurat de «fer tornar agre», de mostrar un aspecte negatiu o evolucionar cap al costat no beneficiós.

2I Hi ha una presència innegable d'expressions que evidencien diferències de gènere i dominació - per part de l'home- del relat cultural i de la fixació d'uns determinats rols que, si avui dia encara perduren, fa uns decennis semblaven inherents a la condició de cada sexe. 22 Variant de mitges amb desafricament. És la pronúncia general a la comarca i en gran part del català occidental.

23 «Porc a mitges, mai fou gras» (DCVB, vol. 8: 75I). 
Farnaques, jònecs i marfantes. La idiosincràsia de l'individu i del poble...

felicitat directes. Així ho reflecteix aquesta dita sentida a Paüls: Bacó fart tomba el bassi. ${ }^{24}$

Quan algú emprèn algun projecte o alguna faena i no en trau res, no li queda res o no n'obté el benefici esperat, una certa parèmia recorre al mateix animal:

Tocina, tocinera; si no m’has dixat res, quina caguera! (Jesús i Maria).

No poden faltar les al-lusions a les defecacions dels animals, que podien tindre alguns usos concrets. El primer pas, però, era conèixer-ne les característiques a través de l'observació directa:

Caguera de bou, quan cau, reganya;

la de burro no, cau apilada (Jesús i Maria).

A Tortosa se'n coneix una altra versió, que es recita amb cantarella:

Caguera de bou, quan plou, s'hi regala;

la de burro no, que cau pilotada.

El coneixement dels costums dels animals domèstics, en general, i de l'aviram, en particular, pot ajudar-nos a l'hora d'adquirir un habitatge o de posar-nos a viure en un edifici amb veïns. El fet és que convé tindre present que «les gallines de dalt sempre han cagat a les de baix» (Roquetes).

Pel que fa a supersticions, la vida pastoral no n'estava exempta. Es veu que «amanir primer les esquelles que el ramat porta malastrugància» (Aldover). Contràriament, «los vells dien que quan tronava i caïen llamps, a les raberes que portaven una auvella negra no els caïen llamps» (Campredó).

Una de les dites més conegudes a la comarca i també estesa pel domini lingüístic és la següent:

Auvella que bela perd lo mos (l'Ampolla, Roquetes, Tortosa).

Pel que fa a les comparacions en què apareixen elements d'aquest camp semàntic, en destaquem aquestes:

«Està més gord que un jònec» ${ }^{25}$ (Raval de Cristo), «Ets més gros que un jònec» (Vinallop).

«Va menos que un burro vell» (Aldover).

«Hi ha més me que al pal d'un galliner» (Aldover), «portes més merda que un pal de galliner»" (el Perelló).

«Sembles una botifarra sacsanuda» ${ }^{26}$ (el Perelló).

24 Recipient que serveix d'abeurador o de menjadora dels porcs.

25 El jònec és un bou de menys de dos anys. Hi ha enquestats que coneixen la comparació i la fan servir, però desconeixien el significat del mot.

26 A l'Ametlla de Mar, Benifallet i el Perelló la baldana rep el nom de botifarra. Tots dos mots són normatius. Pel que fa al qualificatiu, significa «que és gras i té bons sacsons» (DIEC). 


\subsection{Animals vertebrats i invertebrats}

\subsubsection{Insectes}

Sentim a Jesús i Maria la dita següent (coneguda en molts indrets): Al juriol, ni dona ni caragol. Una possible interpretació la trobem en la poca pluja que cau aquest mes, per la qual cosa els caragols són difícils de veure; també pel fet que els caragols es mengen en calent i solen ser un plat fort $i$, per tant, poc recomanable en dies de calor. Pel que fa a l'al-lusió a la dona, hem llegit que per la mateixa raó anterior de les temperatures altes, no ve gaire de gust de tindre-hi relacions sexuals. Moya (I996: 97) tampoc hi sap trobar una explicació definitiva, tot i que, malgrat considerar-lo una «carallotada de refrany», mira de reflexionar-hi:

Si bé en la primera part del refrany és fàcil descobrir un pervers i misògin pensament que perseguiria fer-nos evitar femelles —encara que només fos un mes a l'any-; en canvi, la segona part pot arribar a semblar-nos assenyada i tot: evitar una fartanera dels germans terrestres dels musclos durant aquest mes de calors, i per tant de difícils digestions, sembla força assenyat. Però és precisament per aquesta raó: la perversitat de la primera part i la prudència de la segona, que se'm fa summament irregular veure-hi la relació intel-ligent que pugui haver-hi entre l'una i l'altra.

Això, si no fos, és clar, que allà on l'adagi diu dona haurien de reduir-ho simplement a ús del sexe o jocs amorosos, i que el prosaic (o misogin) exegeta hauria vingut a comparar amb l'ordinari mal de ventre que hipotèticament es derivaria d'una fartanera de cargols durant el mes de la calor. Quina barbaritat!

En qualsevol cas, és una altra mostra de la consideració de la dona com un element més de la realitat i que, com a tal, és susceptible de ser motiu de dites i refranys creats, evidentment, pel sexe masculí, que és qui ha estat, tradicionalment, el protagonista i l'agent dominador de la cultura. En aquest sentit, el coneixement dels refranys i la seua interpretació i transmissió, especialment en l'àmbit escolar, són també una oportunitat per revertir aquesta consideració del sexe femení com a supeditat al masculí i per treballar a l'aula els valors d'igualtat i respecte.

En altres casos, allò que indicava l'insecte no tenia una explicació tan científica ni era fruit de l'experiència: «Quan venia un bumirot ${ }^{27}$ se dia: "Tindrem visita!"» (el Perelló).

Però, a banda d'aquestes facultats positives i, diríem, poc certificables científicament, hi ha insectes que tenen unes propietats negatives i que sí que són demostrables, tot i que és preferible no comprovar-ho:

Pic de xaveta, ${ }^{28}$ la taüt feta (la Cava).

Pic de xaveta, la taüteta (els Reguers).

La forma normativa, per tant, és sacsonuda. El sintagma es refereix a l'embotit doble fet del budell culà.

27 El DCVB recull la forma brumerot: «Borinot, insecte de l'espècie Bombus terrestris (Penedès, Camp de Tarr.)». El terme normatiu que apareix en el DIEC és borinot, insecte himenòpter del gènere Bombus.

28 La xaveta és el nom que rep a gran part del centre i sud del Baix Ebre l'animal conegut amb el terme estàndard escorpí. 
Farnaques, jònecs i marfantes. La idiosincràsia de l'individu i del poble...

Més agradable és l'observació d'insectes com el juriolet, ${ }^{29}$ per la vivesa del seu color roig:

Juriolet, juriolet, trau la camisa al solet (Camarles).

I no només per això, sinó pel seu efecte beneficiós en l'agricultura, ja que es considera un insecte que es menja el pugó. Per un altre costat, de l'Ametlla recorden que amb aquest insecte — que a la població hem recollit amb el nom de palometa- es pronunciaven uns versets entranyables amb l'animalet a la mà: Palometa ves al cel, que et daré un plat de mel, per a tu i per a mi, per a tu i per a mi... I s'anava repetint fins que marxava volant. ${ }^{30}$

No falten tampoc les referències iròniques a una localitat propera. A Paüls ens reciten la següent bertranada, ${ }^{3 \mathrm{I}}$ que al-ludeix al Pinell de Brai, poble veí de la Terra Alta:

Los abegots ${ }^{32}$ del Pinell

pesquen la lluna a la bassa,

en ves $^{33}$ de pescar peix

pesquen fulles de carrasca.

Una comparació pròpia d'aquest camp semàntic conté un joc fonètic:

«Ets ric com un grill» (Camarles).

\subsubsection{Ocells}

Cal anar en compte amb segons quins excrements, no només pel perill d'embrutar-se o de fer pudor, sinó per l'àcid que contenen alguns d'ells: «Si tu agarres una mica de fem de colom, un grapat, i li tires a una florera, ensundemà és morta» (Benifallet). Una constatació similar recollim a l'Ametlla de Mar:

\section{Lo colom minja plata i caga plom.}

29 Conegut també com a marieta, aquest insecte coleòpter (Coccinella septempunctata) rep el nom de juriol (també en diminutiu, com en l'exemple) per homonimització amb el mes de l'any. El DIEC dona entrada al mot poriol i en el DCVB es recull la variant juliol (localitzada a Vinaròs). En les nostres enquestes hem constatat variants com curiolet, guriol, uriolet, buriol. 30 No es tracta d'una pràctica exclusiva de la localitat. En el DCVB descobrim que també es reprodueix a les Balears: «El poriol és un insecte grat als infants, que l'agafen i se'l posen damunt la mà i l'inciten a volar dient-li: "Poriol poriol, veste'n a Maó, | me duràs un mocador | de seda d'es teu color" (Ciutadella)».

3I «La bertranada és una narració protagonitzada per una col-lectivitat de beneits que desconeix les lleis més elementals de la realitat. Moltes vegades aquest tipus de relat és utilitzat pels habitants d'un poble per ridiculitzar els veïns del poble del costat» (Oriol 2002: 62). Aquí, més que una narració, tenim una quarteta rimada.

32 Variant d'abellot, mascle de l'abella.

33 Adaptació a la fonètica catalana del castellanisme vez, usual a la comarca en aquesta expressió: en ves de. 
El corb és un ocell que se sol alimentar d'animals morts, cosa que afavoreix dites com la que transcrivim a continuació, recollida a Camarles. Pel mateix fet de ser animal carronyaire i pel seu color negre, la dita buscava foragitar-lo del lloc on se'l veia, per evitar malastrugança:

\section{Corb, corb, ves a la barraqueta [o a la muntanyeta]}

que tens un matxo mort.

La mateixa percepció negativa sembla dur un altre ocell d'hàbits nocturns: «Les mifes, ${ }^{34}$ diu que quan les sentes cantar porten malastrugància» (Campredó). Moreira (I934) ja recull aquesta superstició: «Si sent cantar la mifa o sent udolar un gos, li entren calfreds de temor i no assossega pensant en quin parent se deurà morir prompte».

També hi ha l'al·lusió amorosa que és propiciada pel cant d'un altre ocell:

\section{La perdiu canta de tarde i el perdigot de matí,}

i la meua enamorada lo domenge de matí (Alfara de Carles).

La comparació "pareixes un capsot del niu» (Paüls) fa referència a una persona que és aturada i curta d'enteniment.

\subsubsection{Peixos}

Hi ha força referències a l'ofici de pescador, no gaire ben remunerat: Peixcador de canya, peixcador de gana (Alfara de Carles). De Camarles recollim les dues fórmules següents:

Pescador de canya, pescador d'ham, se mor de fam.

Pescador de canya, pescador d'ham i moli de vent no li cal notari per a fer el testament.

Hi ha dites que indiquen el període de consum del producte en qüestió:

Lo llissal, de l'agost a Nadal (Paüls).

El consum d'un peix de riu o de mar en una època de l'any ja queda certificat i per escrit amb Cristòfol Despuig, el qual, en l'obra Los col-loquis de la insigne ciutat de Tortosa, a part de ponderar la riquesa i varietat de peixos que es poden trobar al riu i a la mar de l'Ebre, en precisa el mes de l'any més adequat per al seu consum: «Dich que encara que tot l'any se pot menjar de tot lo peix que's mata quan se mata, però és millor quiscum peix en un temps que en altre [...]».35

Quan es diu «està ras com un ull de peix» (Raval de Cristo) s'al·ludeix al cel, net de núvols.

34 Terme que designa l'ocell rapinyaire nocturn de la família dels titònids (Tyto alba), conegut també amb el nom d'òliba. El mot mifa és emprat en gran part de la comarca, especialment a la zona central i meridional.

35 Citat per Vergés, Gomis i Gual (I990: 17). 
Farnaques, jònecs i marfantes. La idiosincràsia de l'individu i del poble...

\subsubsection{Rèptils}

Anteriorment hem comentat el poder mortífer de la picada d'un insecte aràcnid (la xaveta). Descobrim que el mateix efecte advers pot ser produit per la mossegada d'un rèptil prou conegut d'aquestes terres:

Pic d'escurçó, l'estremaunció (Aldover, Jesús, els Reguers).

\subsubsection{Mamífers}

Fixeu-vos en l'expressivitat de les comparacions següents:

«Les ardilletes són més vives que el cagar ajupit» (Roquetes).

«Està com una farnaca» ${ }^{36}$ (Aldover).

«Tins més memòria que un gat» (els Reguers).

«La mustela és més viva que la gana» (Campredó).

\subsection{El temps i les estacions de l'any}

Existeixen força refranys i dites que tenen com a protagonistes la lluna i el sol. Un d'ells, que els ajunta tots dos, es refereix a aquell «halo, cercle lluminós al voltant d'un astre, sobretot de la lluna» (DCVB):

Rogle de lluna, de cada cent, una;

rogle de sol, de cada cent, noranta-nou.

Recollida a l'Aldea, aquesta dita al-ludeix a la probabilitat de pluja segons si el fenomen apareix al sol (probabilitat alta) o a la lluna (probabilitat baixa). Als Reguers hem enregistrat el mateix fenomen amb la mateixa dita però amb una altra paraula:

Si fa redol la lluna, de cada cent ne plou una;

si fa redol lo sol, de cada cent, noranta-nou.

Però el mateix fenomen lunar rep un altre nom, d'etimologia incerta: baldufa, amb les variants galdufa, gandufa... L'eminent dialectòleg Joan Veny (20II: 206) explica que el terme és «d'origen obscur». Potser això explica la resposta que es dona quan algú en pregunta el significat. Aquesta expressió, doncs, es clou amb una evasiva a la pregunta de l'interessat, recollida a Camarles, Tortosa i Vinallop, entre d'altres:

«-La lluna porta gandufa!

-I qué vol dir això?

—Tres pets i una llufa!»

36 El DIEC dona el significat de «llebre jove». Tot i que el mot pot ser desconegut pel parlant, l'expressió al-ludeix a una dona grassa que té poca cura del seu aspecte exterior. 
Manent (2002: 26) també registra aquesta expressió (la lluna fa galdufa) per al mateix fenomen de l'halo en diferents poblacions de la comarca, tot afirmant que no és recollida en el DCVB. ${ }^{37}$

Sobre els núvols, les seues formes i la probabilitat de pluja, les següents dites estan força esteses geogràficament, amb algunes variants:

Los núvols a roquetes, aigua a bassetes (l'Aldea).

Núgols a vaquetes, aigua a les bassetes (Benifallet).

Cel a cabretes, aigua a gotetes (Jesús).

Cel a rajoletes, aigua a bassetes (Aldover).

Cel a roquetes, aigua a bassetes (l'Ampolla, Camarles, Campredó, els Lligallos, Tortosa, Vinallop).

Cel a escaletes, aigua a bufetes (Bítem).

Cel a roquetes, aigua a les cuinetes (el Perelló).

Núvols a bultets, l'aigua a canterets (Alfara).

Cel a muntonets, aigua a cabassets (Xerta).

En altres ocasions, és l'observació de l'efecte que produeixen les gotes en caure a terra el que proporciona informació de la quantitat d'aigua que caurà o de com ho farà:

Aigua a bufetes, aigua a escudelletes (Alfara, els Reguers, Tivenys).

Pluja a bufetes, aigua a bassetes (Camarles).

N'hi ha d'altres, també prou coneguts i estesos geogràficament, que se centren en les descàrregues elèctriques que s'observen al cel:

Llampa a la marina, ventolina;

llampa a la serra, aigua a la terra (Alfara).

Llamps a la marina, ventolina (Aldover).

Llampecs a la marina, ventolada fina (Tortosa).

Llampa a la serra, aigua a la terra (la Cava, els Lligallos).

A les poblacions del sud comarcal, que tenen visió sobre la serra del Montsià, abunden les dites sobre el temps relacionades amb l'observació d'aquesta muntanya de la comarca veïna:

Quan Montsià porta capell no et fies d'ell (la Cava).

Si Montsià porta capell no et fies d'ell (Jesús i Maria).

Montsià porta capell, guarda't d'ell (Camarles).

37 Però, de fet, sí que hi és (DCVB, 6: I30): «Rotlle lluminós al voltant de la lluna, que sol esser senyal de pluja (Tortosa, Torís, Llanera de Ranes). "La lluna porta galdufa; aigua segura"». 
Farnaques, jònecs i marfantes. La idiosincràsia de l'individu i del poble...

\subsection{El cos humà}

Existeix una variada literatura popular sobre afeccions, malalties i els possibles remeis, guaricions o pràctiques per evitar-les. Tot seguit en presentem una mostra:

Si apareixen unes taquetes blanques a les ungles «és que tins falta de calç» (Benifallet).

«Lo fruit del ginebre diu que abans llevava les berrugues» (Xerta).

«Si et posaves boles de ciprés a la butxaca dien que acaminaves millor» (Campredó).

«La cabellera del panís, bullida, servix pel ronyó» (l'Ametlla).

«Pa torrat, amerat en llet, entre dos teles i posat com a cataplasma damunt la panxa, servia per a no fer-se pipi a la nit, perqué dien que era debilitat de panxa» (Aldover).

«Per als rodadits ${ }^{3}$ acalentaves clafoll de ceba, lo clafoll de ceba calentet, i allò te ho curava» (Alfara).

«Antes, en la trementina feen empastres, ${ }^{39}$ quan tenies un gra, per a fe'l rabentar» (els Reguers).

Alguna vegada, a part del remei casolà o natural, no és sobrer encomanar-se al sant encarregat de vetlar per la bona salut d'aquella part del cos en concret:

Sant Blai ditxós mos guàrdia del mal de gola i de tos (Benifallet).

En un lloc tan sensible com l'ull existeix una afectació molt molesta: és allò que popularment rep el nom de mussol. Lingüísticament, aquest és un cas curiós d'homonimització ${ }^{\circ}$ o d'etimologia popular que ha esdevingut normatiu per l'extensió en l'ús. El terme originari és urçol, que és el que prové de l'evolució del terme llatí HORDEOLU. ${ }^{4 \mathrm{I}}$ Doncs es veu que «lo mussol, en un didal de cosir diuen que passa, fregant així» (Paüls). Hi ha altres maneres de fer-lo passar: «Fes-te un nus a la camisa, diu que te se n'anirà lo mussol. O si no, agarres una clau foradada i te la penges dins de l'ull» (la Cava). A Jesús i Maria ens donen un altre remei: «Lo mussol se curava si un carro o un animal tombava un pilonet que havies posat tu a la carretera, en tres pedretes».

Però existeix una altra forma de desfer-se'n, que necessita la col-laboració d'algú altre: "Agafaves una miqueta de sal, en una bosseta, i anaves a consevol casa, que allavons totes les cases estaven aubertes, i dies: “Aquí li dixo el mussol!". I mo n'anàvem corrents» (Roquetes).

38 Cercadits o voltadits al DIEC: «Panadís superficial estès al voltant de les vores unguials.» 39 El mot empastre, variant d'emplastre (forma normativa) amb simplificació del grup consonàntic pretònic, té evidentment aquí el sentit de «Preparació medicinal feta d'una substància pastosa estesa sobre un drap que s'adhereix a la part del cos sobre la qual s'aplica» i no el de «Cosa mal feta» (DIEC).

40 Fenomen pel qual un mot (estrany per al comú de la gent) s'atansa a un altre (més conegut o popular) pel seu paregut formal, sense que el significat hi tinga res a veure.

4I Diminutiu d'HORDEU (que significa ordi), i que s'aplica a aquest granet molest de la parpella per la seua semblança amb el gra del cereal. 
De l'afecció estomacal coneguda amb el nom estàndard de diarrea no calia preocupar-se'n gaire, tal com ens diu un informant: «Los vells dien: "les cagueres rai, que cagant passen!"» (Tivenys). Hi sobren comentaris.

\subsubsection{Qualitats i defectes humans}

Sobre la droperia. «Són més gossos que el jaure» (Xerta). «És una manta morellana» (Xerta). «Li fa gonia ${ }^{42}$ hasta la seua sombra» (Bítem). En ocasions, no pas per mandra sinó amb motiu justificat, «quan a algú li carregaven d'una faena pesada dien: "T’han ficat lo jou"» (l'Ampolla).

Sobre l'embriaguesa: «Te s'han fet los peus redons, que no t'aguantes dret!» (Xerta).

Sobre l'edat: “"Estàs fet un gueato", se diu quan un se fa vell» (l'Ampolla).

Sobre la força de voluntat: «Lo cap fa anar els peus» (Paüls). En deixem constància per voluntat expressa de l'informant, que ens digué: «Apunta-ho també».

Les comparacions recollides en aquest apartat són aquestes:

«A una dona grossa i mal vestida se li diu: "Pareixes una marfanta!"» (Benifallet).

«Ets més viva que un peix» (l'Ampolla).

«Estic suada com una mar» (l'Ampolla).

«És amarg com la fel» (els Reguers).

«És fart com la cangrena» (Raval de Cristo).

\subsection{La casa}

Sobre l'indret on edificar-se la casa, al Baix Ebre es té molt clara una cosa: A la vora del riu no faces lo niu (Bítem). I és que gairebé totes les persones de pobles riberencs de l'Ebre amb les quals hem parlat tenen algun record d'inundacions o crescudes de l'Ebre i del perill que comportaven. Amb la construcció, al segle passat, dels embassaments aigües amunt, el fenomen s'ha vist reduït pràcticament a episodis molt excepcionals.

Sobre el cànter com a recipient per a l'aigua, hi ha la popular dita Cànter nou, aigua fresca (Aldover), que evidencia els efectes positius que pot arribar a comportar el canvi o renovació.

Xerta era coneguda pels seus torrons. La seua fama superava els límits de la comarca. De la dedicació i elaboració artesanal d'aquest dolç nadalenc n'havia de quedar alguna traça en forma de fraseologia, que és la manera com més fixada queda una realitat en la memòria de la gent:

De Xerta baixen torrons embolicats en paper perqué no s'arrofreden al passar per Aldover.

42 Terme usat aquí en el sentit d'angúnia, preocupació o malestar. Té altres sentits, com molt bé certifica Beltran (2OIO, I: 443-444). Formalment, deriva d'agonia, amb afèresi de la $a$ inicial per fonètica sintàctica. 
Farnaques, jònecs i marfantes. La idiosincràsia de l'individu i del poble...

Acabarem aquest apartat amb una cançó que ens va entonar una informant de Tortosa. Recull la virtut de l'estalvi simbolitzada en un objecte que representa el seny a l'hora de controlar les despeses i de pensar en les necessitats del futur: la vidriola. ${ }^{43}$

La vidriola és molt bonica, si està plena encara més. Que contenta jo estaria si desada la tingués! No hi ha més que calderilla, per les xiques també n'hi ha, les pessetes van escasses com al món los hòmens sants.

Tring! Tring! Tring!

Adepreneu, arrecolliu, perqué així quan sirem vells en bon llit podrem dormir.

Jo en conec una xiqueta que no ti res al seu cap, quan sa mare se n'adona la vidriola ja ha trencat. Esta xica que tant gasta no tindrà mai cap diner, en ser gran si no s'esmera lo seu llit serà un paller. Adepreneu, arrecolliu, perqué així quan sirem vells en bon llit podrem dormir.

Jo en conec un noi molt murri que no ti res al seu cap, quan sa mare se n'adona la vidriola ja ha trencat. Este xiquet que tant gasta no tindrà mai cap diner, en ser gran si no s'esmera lo seu llit serà un paller Tring! Tring! Tring!

43 És un mot normatiu i, com a tal, es pot dir i es pot escriure. 
La vidriola ja es va omplint-se!

Tring! Tring! Tring!

Casi plena ja la tinc!

Comparacions relacionades amb aquest camp:

«Això està negre com un tió» (Alfara de Carles).

«És més negre que un tió» (Bítem).

«Ets més dropo que una manta nova» (Raval de Cristo).

\subsection{La família. El cicle de la vida}

Quan una dona està en estat se li diu: «Menjaràs confits!» (Benifallet). Era la llepolia que es repartia en la celebració del bateig de la criatura. L'expressió es converteix en una alternativa eufemística per no haver de dir que una dona està embarassada. Però si els padrins eren avars o, per qualsevol motiu, no oferien llepolies als assistents en acabar la celebració, se'ls dedicava un crit unànime: «Padrí sense bocí!», que també tenia el corresponent femení, «Padrina sense bocina!» (Camarles).

De fets extraordinaris també se n'expliquen. N'hi ha un que va tindre lloc a Xerta i que podria ser considerat un relat sobre una experiència real, concretament un exemple de succeït: ${ }^{4}$

Si Egipte va tindre el Nilo i va tindre Moisés,

a Xerta també un xiquet se va salvar dins d'un bres.

En aquest cas, no es presentaria com un relat extens, sinó sintetitzat en una expressió fixada i rimada que en facilita la transmissió oral i la gravació a la memòria col-lectiva.

A vegades, per iniciar una relació o fer notar que una persona ens agrada pareix que qualsevol mètode serveix, fins i tot un d'aparentment oposat:

Qui tira pedretes tira amoretes (Xerta).

\subsection{Les festes populars i religioses}

Abans de la Quaresma se celebra el Carnaval, que comença tradicionalment el Dijous Llarder (o Dijous Jarder, tal com es diu al Baix Ebre). És típic aquest dia sortir a berenar o anar a «menjar la truita» en algun paratge particular de la població; però, encara que és una pràctica força arrelada als pobles on se celebra, no és general a la comarca. Al Perelló i a l'Ametlla de Mar, per exemple, és una tradició que no se segueix. Sí que es fa a Xerta, d'on recollim la següent cantarella (també sentida a Aldover):

44 «El succeit és un tipus de relat sobre experiències reals que explica un esdeveniment que ha tingut lloc en la comunitat del narrador i que és recordat especialment pel seu caràcter sorprenent, pel seu dramatisme, o per la curiositat de la situació creada» (Oriol 2002: 80). 
Farnaques, jònecs i marfantes. La idiosincràsia de l'individu i del poble...

Lo Dijous Jarder, fogasseta, fogasseta,

lo Dijous Jarder, fogasseta minjaré.

El Divendres Sant és una jornada que porta associades moltes creences particulars. No descobrim res de nou si constatem que és un dia òptim per anar a collir timó o farigola (anomenada frígola a la part central i meridional del Baix Ebre), tal com ho certifica la dita: Divendres Sant a collir frígola al camp (Bayerri I936, I: 504). Però hi ha supersticions que van més enllà: «Si beneïxes en aigua bendita, no hi han escarabitxes ${ }^{45}$ a casa; i si en Divendres Sant agranes u fregues, tins més escarabitxes a casa. Jo t'asseguro que un Divendres Sant vaig fregar i vaig dir que no fregaria més, perquè vaig tindre tot lo sant any escarabitxes a casa» (Alfara de Carles).

La Setmana Santa en general i la festa de Pasqua en particular són, doncs, molt riques en aquest sentit. Pel mateix dia de Pasqua, «quan repicaven les campanes, quan representa que ressuscita Nostre Sinyor, ma iaia mos fea picar a la paret i dient: Xinxes i caparres sortiu del forat, que Nostre Sinyor ha ressuscitat!» (Benifallet). La informant s'emociona en recordar les paraules de sa iaia. Una altra informant afirma que «lo dia de Pasqua, quan repicaven les campanes, mos feien plegar arena del carrer i en un pot la guardàvem i representava que en aquell moment estava beneïda. I quan hi havia una gran tronada se tirava pel carrer, esta arena» (Aldover). Es tracta, per tant, d'un altre signe de protecció davant de les adversitats.

Era freqüent que colles de xiquets anessen pels carrers del poble cridant els fidels a la celebració dels oficis litúrgics, especialment els de la Setmana Santa. La seua veu unànime se sentia, sovint, acompanyada de carraus i altres instruments de fer soroll: «Homes i dones a missa, al primer toc». No faltaven, però, les versions més o menys gracioses, com la que ens van dir a Alfara:

Dones dones, a missa; a dormir a la pallissa.

Dones dones al sermó, a dormir al pallissó.

L'última comparació que oferim és la següent:

«Ets un pendó, que sempre estàs pel carrer» (Aldover).

\section{Conclusions}

En ple segle XXI, parlar de cultura popular i de folklore pren tot el sentit. Els temps canvien i les eines informàtiques i la connexió a Internet ens proporcionen un ventall immens de recursos i un accés gairebé il-limitat al coneixement. Tot això pertany, sobretot, al camp de la recol-lecció i de la distribució. El que pretenem remarcar és que una de les eines fonamentals de creació i de transmissió de la cultura popular és l'oralitat. ${ }^{46}$

45 Escarabat de cuina o panerola, al DIEC; escarabatera, en el DCVB. Terme del dialecte tortosí $\mathrm{amb}$ què ens referim a aquest insecte que cerca hàbitats propis dels humans, especialment les cuines i els lavabos (vegeu Beltran 20IO, I: 333-334).

46 En podeu veure una mostra magnífica a l'obra de Gargallo i Pradilla (I997), centrada en la població de Rossell (Baix Maestrat). 
El text oral és el que predomina innegablement en les nostres relacions quotidianes. I és en l'oralitat on es generen quantitat de manifestacions populars i folklòriques, des de grans rondalles fins a fórmules fraseològiques com la següent, amb què es respon amb una evasiva la demanda de la satisfacció d'una necessitat fisiològica:

«-Tinc gana!

-Pega't un mos a la cama i menjaràs baldana». ${ }^{47}$

I cal tindre present que l'oralitat s'acompanya de moltes manifestacions del llenguatge no verbal, que proporcionen al text emès una vitalitat i una quantitat d'informació que el text escrit no pot reproduir. La gestualitat, la mirada, el silenci, el volum i el to de la veu, la postura del cos. És per això que hem d'aprofitar qualsevol oportunitat per transmetre aquest cabal cultural: els pares a casa explicant contes o històries locals als fills, els mestres a escola treballant no només les manifestacions populars més generals, sinó les particulars de cada poble, i cada persona mirant de mantenir vives les expressions del seu parlar.

També són eines d'una vàlua innegable les biblioteques, que cada vegada compten amb especialistes més preparats que ofereixen una gran quantitat d'activitats en aquesta direcció. I no hem d'oblidar altres actors de manteniment i propagació de les tradicions com són els esplais amb els monitors i les diferents activitats lúdiques que munten, en especial les colònies o els campaments, on més d'un segur que recordarà haver après una cançó, una rondalla, una llegenda urbana o una història de temor.

Si es vol aconseguir això, si creiem que tenim una cultura que cal preservar, serà necessari revalorar la memòria. És una de les grans damnificades de certes tendències educatives, que feien posar l'accent de l'aprenentatge exclusivament en la pedagogia activa. Com va dir no fa gaire l'escriptor gallec Manuel Rivas en un article, «la memòria no té a veure amb el passat, té a veure amb el coneixement». Així, doncs, la memòria, quan la verbalitzem, reflecteix la percepció que tenim del món i ens dona cohesió en la línia temporal, perquè lliga el que ens deien els nostres iaios amb el que nosaltres direm als nostres nets algun dia. Si volem trobar sentit a la nostra vida, el primer pas per fer és saber d'on venim.

47 A la major part del Baix Ebre, botifarra d'arròs, ceba, greix i sang. 
Farnaques, jònecs i marfantes. La idiosincràsia de l'individu i del poble...

\section{Referències bibliogràfiques}

Alcover, Antoni M.; Francesc de B. Moll (1985): Diccionari català-valencià-balear. Palma: Moll, Io vols.

BAYERRI, Enric (I936): Refraner català de la comarca de Tortosa. Tortosa: Editorial la Gráfica, 4 vols.

Beltran, Joan (20IO): Vocabulari de Cruïlla. Els mots de les Terres de l'Ebre i del Maestrat en el context del català formal. Benicarló: Onada Edicions, 2 vols.

DCVB = AlCOVER; MOLL (I985).

CASTEllà, Carles M. (20I7): Cultura popular, folklore i etnologia del Baix Ebre. Recull de mots, dites, creences, supersticions, etnotextos. Benicarló: Onada Edicions.

GARgallo, José Enrique; Miquel Àngel Pradilla (I997): El joc ancestral de la paraula. Llengua, cultura popular i refranyer a Rossell (Baix Maestrat). Benicarló: Associació Cultural Alambor.

Gimeno, Lluís (I997): Atles lingüístic de la diòcesi de Tortosa. Barcelona: Institut d'Estudis Catalans.

Grup de Recerca Científica Terres de l'Ebre (2008): Plantes del Port, I. Tortosa: Grup de Recerca Científica Terres de l'Ebre.

- (2009): Plantes del Port, II. Tortosa: Grup de Recerca Científica Terres de l'Ebre.

- (20IO): Plantes del Port, III. Tortosa: Grup de Recerca Científica Terres de l'Ebre.

MANENT, Albert (2002): Els noms populars de núvols, boires i vents del Baix Ebre $i$ Baix Llobregat. Vilassar de Mar: Katelani.

MoreIRA, Joan (I934): Del folklore tortosí. Costums, ballets, pregàries, tradicions, jocs i cançons del camp i de la ciutat de Tortosa. Tortosa: Impremta Querol.

MoyA, Bienve (I996): Calendes. Impressions sobre mites, festes i celebracions catalanes. Tarragona: Edicions El Mèdol.

OrIOL, Carme (2002): Introducció a l'etnopoètica. Teoria i formes del folklore en la cultura catalana. Valls: Cossetània Edicions.

RomeU, Josep (I993): Materials i estudis de folklore. Barcelona: Editorial Alta Fulla.

- (2000): Recerques d'etnologia i folklore. Barcelona: Publicacions de l'Abadia de Montserrat.

VAllès, Joan (dir.) (20I4): Noms de plantes. Corpus de fitonímia catalana. Barcelona: TERMCAT, Centre de Terminologia (Diccionaris en Línia) <http://www. termcat.cat/ca/Diccionaris_En_Linia/I9I/> [data de consulta: maig de 20I8].

VenY, Joan (2007): Petit atles lingüístic del domini català. Barcelona: Institut d'Estudis Catalans, vol. I.

- (2009): Petit atles lingüístic del domini català. Barcelona: Institut d'Estudis Catalans, vol. 2.

- (2OII): Petit atles lingüístic del domini català. Barcelona: Institut d'Estudis Catalans, vol. 3 .

- (20I3): Petit atles lingüístic del domini català. Barcelona: Institut d'Estudis Catalans, vol. 4. 
Carles M. Castellà Espuny

VENY, Joan (2OI5): Petit atles lingüístic del domini català. Barcelona: Institut d'Estudis Catalans, vol. 5.

- (20I7): Petit atles lingüístic del domini català. Barcelona: Institut d'Estudis Catalans, vol. 6.

Vergés, Gerard; Ramon Gomis; Josep GuAL (I990): Barques i fogons. De Vinaròs a Calafell. Tarragona: Edicions El Mèdol. 